\title{
Self-evaluation maintenance in sports team rivalries
}

\author{
ROBERT A. REEVES \\ Augusta College, Augusta, Georgia \\ and \\ ABRAHAM TESSER \\ University of Georgia, Athens, Georgia \\ (Delwin D. Cahoon, sponsor)
}

\begin{abstract}
An experiment was conducted to test the generality of a self-evaluation maintenance model of behavior in a situation involving individuals' associations with a group. Male and female undergraduates completed a sports team questionnaire, which assessed their preferences to see both psychologically close and distant opponents of their home team win in high-relevance (football) and low-relevance (water polo) sports contests. As predicted from the model, participants preferred psychologically close opponents to win more in the low- than in the high-relevance sport, but preferred psychologically distant opponents to win more in the high- than in the low-relevance sport. Participants also preferred close opponents to win more than distant opponents. Implications for group identification and reference-group influences are discussed.
\end{abstract}

The purpose of this study was to test a self-evaluation maintenance model (Tesser, in press) of social behavior. Self-evaluation is treated in this model as a hypothetical construct which represents the relative worth that persons assign to themselves or that they believe others assign to them. It is assumed that individuals behave in ways that maximize their self-evaluation and that self-evaluation depends partially upon associations with others. The model proposes two processes, reflection and comparison, and a weighting factor, relevance, which determines whether reflection or comparison will come into play.

Reflection is the process operating in cases in which association enhances self-evaluation. The effectiveness of reflection in increasing self-evaluation depends upon two components-closeness and performance. One person must be psychologically close to another, and that person must perform well on some dimension, for reflection to increase the first person's self-evaluation. The comparison process operates in situations in which association may lower self-evaluation. Here, also, closeness and performance are implicated. Association with a close other who performs well on some dimension may lower selfevaluation, that is, a person's performance may pale in comparison to that of another.

An earlier version of this paper was presented at the 1984 meeting of the Southeastern Psychological Association in Atlanta, GA. We would like to thank Del Cahoon and Steve Hobbs for their assistance. Reprint requests should be sent to Robert A. Reeves, Department of Psychology, Augusta College, Augusta, GA 30910, or to Abraham Tesser, Institute for Behavioral Research, University of Georgia, Athens, GA 30602 .
The relative import of the reflection and comparison processes is determined by relevance, or the extent to which the performance dimension in question is selfdefining for the person. When relevance is low, association with a close, high-performing other should increase self-evaluation through the reflection process. However, when relevance is high, association with a close, highperforming other should lower self-evaluation, as the comparison process would occur.

The model has received support in several studies of interpersonal behavior (Tesser, 1980; Tesser \& Campbell, 1980; Tesser \& Paulhus, 1983). The present study tested the general applicability of the model in explaining self-evaluation maintenance in relation to association with a group. We first assumed that one's school identification is an important part of self-definition. Therefore, reasoning from the model, we assumed that students' self-evaluation would be enhanced if university athletic teams of psychologically close schools performed well in sports that were low in relevance and that self-evaluation would be lowered if close schools performed well in sports that were high in relevance. It was predicted that, in order to maintain high self-evaluation, students would prefer to see a close school win more in a low-relevant sport and win less in a high-relevant sport in relation to a less close, or distant, school.

\section{METHOD}

\author{
Subjects \\ Participants were 38 undergraduates of the University of Georgia, \\ who participated for course credit.
}




\section{Procedure}

The design was a 2 (relevance) $\times 2$ (closeness) within-subjects design. Each student completed a sports team questionnaire by responding to a series of imagined sports contests between Georgia and Southeastern Conference opponents in either football, a high-relevance sport, or water polo, a low-relevance sport. After each contest, participants indicated on a seven-point scale how strongly they preferred to see Georgia's opponent win a similar contest with each of the remaining conference teams. Closeness of schools had been defined for each participant by their responses on a four-point scale indicating how often each of the other nine schools in the conference came to mind when they thought of Georgia. Close schools were those which came to mind always or often; distant schools were those which came to mind sometimes or never.

\section{RESULTS AND DISCUSSION}

Because preliminary analyses revealed no main or interactive effects involving participants' sex, the analyses reported have been collapsed across this variable. Analysis of variance of preference for winning scores revealed a significant main effect of closeness $[F(1,37)=10.36$, $\mathrm{p}<.003]$ and a significant relevance $\times$ closeness interaction $[F(1,37)=8.15, p<.007]$ (see Figure 1$)$. The main effect of closeness indicated that participants preferred close schools (mean $=4.97$ ) to win more than distant schools (mean $=3.15$ ). The relevance $\times$ closeness interaction revealed, as predicted, that participants preferred close schools to win more in the low-relevance $($ mean $=5.17)$ than in the high-relevance $($ mean $=4.77)$

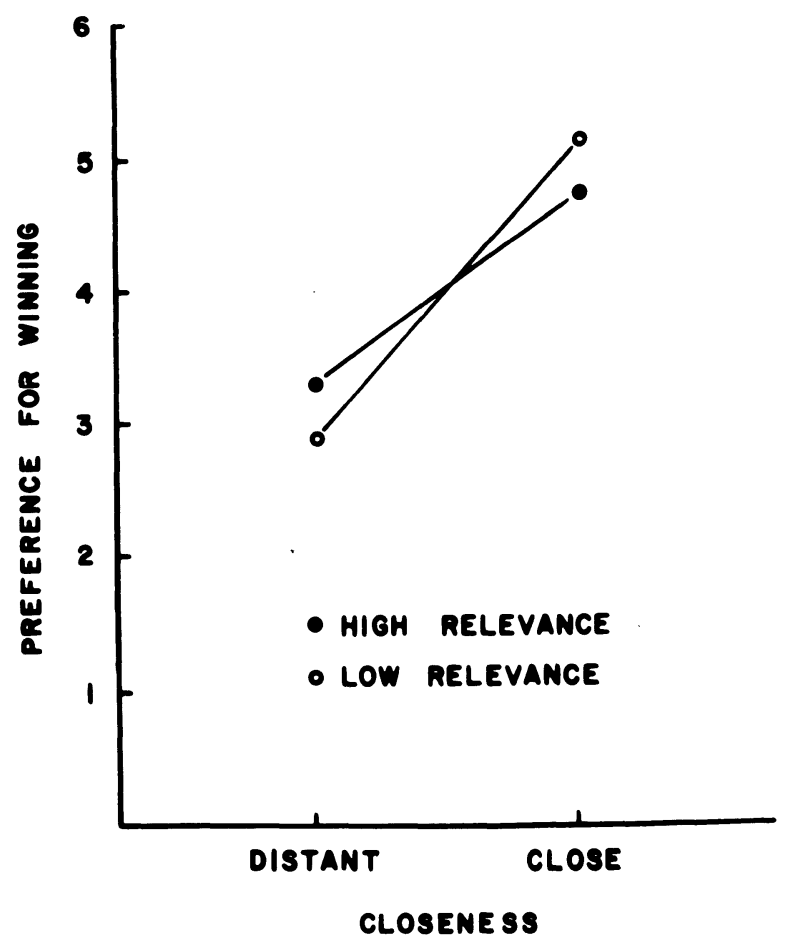

Figure 1. Mean preference for opponents to win as a function of closeness and relevance. sport, but preferred distant schools to win more in the high-relevance $($ mean $=3.29)$ than the low-relevance (mean $=2.9$ ) sport.

The results of this study support the self-evaluation maintenance model hypothesis. Although participants preferred close schools to win more than distant schools, this preference was qualified by the relevance $\times$ closeness interaction, as predicted. This interaction can be interpreted in terms of the model as follows. If a close school were to win (i.e., perform well) in a high-relevance sport, the comparison process would come into play and the selfevaluation of the person would be lowered. Therefore, to enhance self-evaluation, the person should prefer to see the close school perform more poorly than the distant school in the high-relevance sport.

On the other hand, if a close school were to win (i.e., perform well) in a sport low in relevance, the reflection process would come into play and the person's selfevaluation would be enhanced by the reflected glory of the close school. In this case, the person should prefer that the close school perform better than the distant school in the low-relevance sport.

The implications for group identification and referencegroup influences are clear. Obviously, people want their own group to be a winner. For example, Cialdini et al. (1976; cf. also Cialdini \& Richardson, 1980) found that students at universities known for their football teams wore more school-related clothing on Mondays following victories by their home teams than on Mondays following defeats. Also, students discussing the outcome of a football game were more likely to use the pronoun "we" in describing the game when their home team had won than when it had lost. Furthermore, this tendency was more pronounced when the students had previously been made to fail a test publicly.

The present line of research also suggests that people prefer to see groups that are psychologically close to their own group perform well. However, this closeness effect is moderated in a predictable way by the relevance of the activity. Since high performance on a high-relevance activity can be threatening to one's own group (by comparison), the preference for a good performance by a group close to one's own is greater on a low-relevance activity.

In conclusion, this study has demonstrated the utility of extending the self-evaluation maintenance model to associations between individuals and groups, in addition to the previously studied interpersonal associations.

\section{REFERENCES}

Cialdini, R. B., Borden, R. J., Thorne, A., Walker, M. R., FreeMAN, S., \& SLOAN, L. R. (1976). Basking in reflected glory: Three (football) field studies. Journal of Personality \& Social Psychology, 34, 366-375.

Cialdini, R. B., \& Richardson, K. D. (1980). Two indirect tactics of image management: Basking and blasting. Journal of Personality \& Social Psychology, 39, 406-415. 
TESSER, A. (1980). Self-esteem maintenance in family dynamics. Journal of Personality \& Social Psychology, 39, 77-91.

TESSER, A. (in press). Some effects of self-evaluation maintenance on cognition and action. In R. M. Sorrentino \& E. T. Higgins (Eds.), The handbook of motivation and cognition: Foundations of social behavior. New York: Guilford Press.

Tesser, A., \& CAMPBEll, J. (1980). Self-definition: The impact of the relative performance and similarity of others. Social Psychology Quarterly, 43, 341-347.

Tesser, A., \& Paulhus, D. (1983). The definition of self: Private and public self-evaluation management strategies. Journal of Personality \& Social Psychology, 44, 672-682.

(Manuscript received February 26, 1985.) 